Journal of Extension Education

Vol. 29 No. 3, 2017

DOI:https: / / doi.org/10.26725/JEE.2017.3.29.5921-5924

\title{
Knowledge of Recommended Pesticide usage among Cabbage Growers
}

\section{Naveen Kumar ${ }^{1}$ and S. Palanisamy ${ }^{2}+$}

\begin{abstract}
This study aimed to access the knowledge level of cabbage growers on recommended pesticide usage practices. It was carried out in two blocks of Krishnagiri district of Tamil Nadu. Krishnagiri district was selected based on maximum acreage under cabbage cultivation. Two blocks viz., Shoolagiri and Hosur were selected considering the area covered under cabbage. A sample of 120 cabbage growers was selected random selected for the study. A well structured interview schedule was used for data collection and collected data were analyzed using appropriate statistical tools. The findings of the study revealed that majority of the cabbage growers had medium to low level of knowledge on recommended pesticides usage.
\end{abstract}

Keywords : Cabbage; knowledge level; Pesticide usage; Tamil Nadu

Cabbage (Brassica oleracea) is a leafy green vegetable crop and dense multi-layered vegetable. Cabbage is a good source of vitamin $\mathrm{K}$, vitamin $\mathrm{C}$ and dietary fiber, mostly cultivated in northern India as it requires cooler climate to grow. Its annual output in India is around 90.39 lakh tonnes from an area of more than 4 Lakh hectares. At present, the states of West Bengal and Odisha are the largest producers of cabbage in India. There is a wide gap between the present availability and the vegetable demand per person/day. The area and production of vegetables are increasing year after year after the green revolution. Vegetable cultivation had increased in India from 55.93 Lakh ha in 1992 to 93.96 Lakh ha in 2014 (National Horticulture Board, 2014). India contributes about 14 per cent of the world vegetable production and occupies first position in okra \& chickpea production in the world.

Noted scientist Norman Borlaug had indicated that, the whole ban on pesticide use in agriculture might result in 50 per cent reduction in crop production and 4-5 fold increase in food prices. Pesticides are still the most important key in pest management and it is also found to be responsible for increasing the yield in cabbage crop. On the other

1. Relationship Manger, HDFC Bank, Pudupatti Road, Tirupathur - 635601 and 2. Former Professor \& Head, Training Division, Directorate of Extension Education, Tamil Nadu Agricultural University, Coimbatore - 641003

十Deceased

Received : 15-08-2017; Accepted : 19-09-2017 
hand there is a serious concern about the indiscriminate use of pesticides. Tamil Nadu had ranked first in usage of pesticides in India in 2010 (Pesticide and Documentation unit, 2010).

Experts feel that the damage caused by prolonged pesticide use could be minimized if farmers use them at recommended donage. Hence the present study was designed to find out the knowledge level of recommended use of pesticides among cabbage growers. Based on the results of the study, appropriate extension training strategies can be formulated.

\section{METHODOLOGY}

\section{This study was conducted at Shoolagiri and Hosur blocks of Krishnagiri district in Tamil Nadu as it is one of the major cabbage growing districts in the state. Fourteen independent variables and one dependent variable namely knowledge about recommended pesticide usage among cabbage growers were selected based on discussion with extension scientists and extension practitioners.}

Data were collected by using a wellstructured and pre-tested interview schedule. The data collected were coded, tabulated and analyzed using mean, percentage, correlation and multiple regressions for interpretation. Straight questions were asked in respect of variety, seed treatment, recommended pesticides, dosage, traps used, and pests of cabbage crop. The photographs of the symptoms of pest and diseases were used to ascertain the knowledge level of cabbage growers. Based on the total score, the cabbage growers were classified into low, medium and high knowledge level categories using mean and standard deviation.

\section{FINDINGS AND DISCUSSION \\ Knowledge level of Cabbage Growers}

The study revealed that majority of the cabbage growers (43.33\%) had medium level of knowledge followed by low (33.33\%) and high (23.34\%) levels. This might be due to the fact that majority of them had medium level extension agency contact, better level of scientific orientation and most of the farmers were middle aged. The findings are in conformity with the results of Jeyalakshmi (2004).

\section{Practice-wise Knowledge level of Cabbage Growers on the Recommended Pesticide usage}

Attempts were made to find out the practice wise knowledge level of the cabbage growers. The results are presented in Table 1.

It could be observed from Table 1 that more than 95 per cent of the cabbage growers had knowledge on major pests of cabbage. More than 85 per cent of the cabbage growers had knowledge on use of traps to control aphids in cabbage cultivation and knowledge on following the recommended dosage of pesticides. 
Table 1.

Practice wise Knowledge Level on the Recommended Pesticide Usage followed by Cabbage Growers

\begin{tabular}{|c|l|c|c|}
\hline \multicolumn{1}{|c|}{ S1. No. } & \multicolumn{1}{|c|}{ Statements } & Number* & Per cent \\
\hline 1. & $\begin{array}{l}\text { Recommended seed treatment chemical used in } \\
\text { cabbage }\end{array}$ & 89 & 74.16 \\
\hline 2. & Knowledge about recommended pesticides & 97 & 80.83 \\
\hline 3. & Major pests of cabbage & 116 & 96.66 \\
\hline 4. & Symptoms of diamond backmoth infestation & 93 & 77.50 \\
\hline 5. & $\begin{array}{l}\text { Recommended control measure for leaf spots in } \\
\text { cabbage }\end{array}$ & 88 & 73.66 \\
\hline 6. & Recommended pesticides for diamond back moth & 71 & 59.16 \\
\hline 7. & Recommended control measure for downy mildew & 92 & 76.66 \\
\hline 8. & $\begin{array}{l}\text { Methods of seed treatment used to manage club } \\
\text { root diseases }\end{array}$ & 73 & 60.83 \\
\hline 9. & $\begin{array}{l}\text { Recommended management measure used to } \\
\text { control cut worms }\end{array}$ & 91 & 75.83 \\
\hline 11. & Fraps used to control aphids & 104 & 86.66 \\
\hline
\end{tabular}

(* Multiple responses)

The identification of major pests by the cabbage growers was mainly based on experience. More than 80 per cent of the respondents had knowledge on recommended chemical pesticides for the cabbage pests, while over 70 per cent of the cabbage growers had knowledge on symptoms of diamond-back moth, recommended control measure for downy mildew, cutworms and leaf spots.

It was observed that 60.83 per cent of the respondents had knowledge on seed treatment used to control the club root diseases. Farmers mostly buy already treated seeds from branded companies which are sold in bags of different sizes. This might be the reason for not knowing about the seed treatment methods.

Only 59.16 per cent of the respondents had knowledge on the recommended pesticides for Diamondback moth. Though the farmers identify the major pests of cabbage easily, they lack knowledge on application of 
recommended chemical pesticides to the specific pests and more respondents apply high dosage of pesticides without knowing the population of insect pests, natural enemies and the crop condition.

By this study, one could interpret that farmers are growing cabbage only for commercial purpose and not for their own consumption, which could have been the reason for not giving importance on the pesticide residues and harmful effects of chemicals. Waiting period was not taken into consideration and frequent spraying of pesticides without knowing the threshold level was being done. Hence, the farmers should be encouraged to attend trainings, meetings, demonstrations and watch agricultural programmes on pesticide usage. Suitable training strategies need to be formulated to educate the farmers on handling of recommended pesticides and spraying methods.

\section{REFERENCES}

Jayalakshmi, M. (2004). Awareness, Knowledge and Adoption of Organic Farming Practices Among Tribal Farm Women. Unpublished M.Sc. (Ag.) Thesis, AC\&RI, TNAU, Coimbatore.

National Horticultural Board. (2015). All India Area, Production and Productivity of Vegetables in 2014-2015. Indian Horticultural Database. Retrieved from www.nhb.gov.in.

Pesticide and Documentation Unit. (2010). Statewise Demand of Pesticides During the Last Five Years 200506 to 2009-10. Retrieved from www. Indiastat.Com 